\title{
Fronteiras Sul-americanas: História, formas e processos contemporâneos
}

\author{
Adriana Dorfman' \\ Arthur Borba Colen França" \\ Marla Barbosa Assumpção"I
}

\section{RESUMO}

O presente trabalho visa traçar um panorama das fronteiras sul-americanas. Para tanto, foram analisados os processos de formação dessas fronteiras desde o período da conquista do subcontinente pelos reinos europeus, no final do século XV e início do XVI, e da colonização que se estendeu por três séculos. Em seguida, examinou-se o processo de independência dos países da região, no século XIX. Além disso, elencamos os principais conflitos que marcaram, no passado e no presente, a história desses países, sobretudo contendas envolvendo disputas territoriais na conformação das fronteiras da região. As principais formas assumidas pelas fronteiras sul-americanas (frontera, fronteira, frente) são sumarizadas. Por fim, foram abordadas as iniciativas recentes de integração regional.

PALAVRAS-CHAVE: Fronteira, América do Sul, Conflitos, Integração Regional

I Professora do Departamento de Geografia e do Programa de Pós-Graduação em Geografia da Universidade Federal do Rio Grande do Sul. Coordenadora do projeto Unbral Fronteiras - Portal deAcesso Aberto das Universidades Brasileiras sobre Limites e Fronteiras. Líder do GREFIT - Grupo de Pesquisas Espaço Fronteira Informação Tecnologia. E-mail: adriana.dorfman@ufrgs.br

II Bacharel em Relações Internacionais pela Universidade Federal do Rio Grande do Sul, Membro da equipe de pesquisa do projeto Unbral Fronteiras - Portal de Acesso Aberto das Universidades Brasileiras sobre Limites e Fronteiras e do GREFIT - Grupo de Pesquisas Espaço Fronteira Informação Tecnologia.

E-mail: arthurlunabcf@outlook.com

III Licenciada e Mestre em História pela Universidade Federal do Rio Grande do Sul; Técnica em Assuntos Educacionais no Instituto Federal de Educação, Ciência e Tecnologia do Rio Grande do Sul. E-mail: marlalua@yahoo.com.br 


\section{APRESENTAÇÃO}

O território hoje conhecido como América do Sul foi conquistado e colonizado pelos reinos da Península Ibérica, Portugal e Espanha, a partir do final do século XV e início do XVI. A primeira divisão entre as possessões das duas coroas foi estabelecida pelo Tratado de Tordesilhas (1494), no qual as terras já ou a serem descobertas no Novo Mundo foram divididas entre Portugal e Castela. O tratado estabelece o meridiano $370^{\circ}$ para o Ocidente dos Açores como 0 limite entre futuras possessões de Portugal (a leste da linha) e Espanha (a Oeste) (mapa 1).

A exploração formal dessas possessões terminou depois de mais de três séculos. Hoje, existem doze países na América do Sul, embora colônias e outras dependências ainda possam ser encontradas no continente.

A colonização foi baseada na extração de metais preciosos e em plantações (plantations), cuja produção era enviada principalmente para os mercados metropolitanos. Entre as características da colonização da América do Sul está a dizimação dos povos indígenas. Outro traço importante foi o lucrativo comércio de escravos, que ligava a Europa, a África e a América através do Oceano Atlântico.

Muitas fronteiras entre as coroas ibéricas, e mais tarde entre os países independentes, foram construídas seguindo a experiência Ibérica / Moura. Na Baixa Idade Média (período que se estendeu do século XI ao XV), o termo frontera (fronteira, em Português) já era amplamente conhecido: práticas de intercâmbios e alianças que se fundiram com ações ofensivas e defensivas foram constitutivas das relações entre os cristãos e os reinos muçulmanos (ZUSMAN, 2000). Na América do Sul, bem como na Península Ibérica, as cidades de fronteira, muitas vezes, agiram como pequenos fortes, sendo na sua origem uma linha de front $e$, hoje, as muitas cidades-gêmeas. 
Mapa 1: Meridiano de Tordesilhas: a primeira fronteira moderna da América Sul - Capitanias Brasileiras

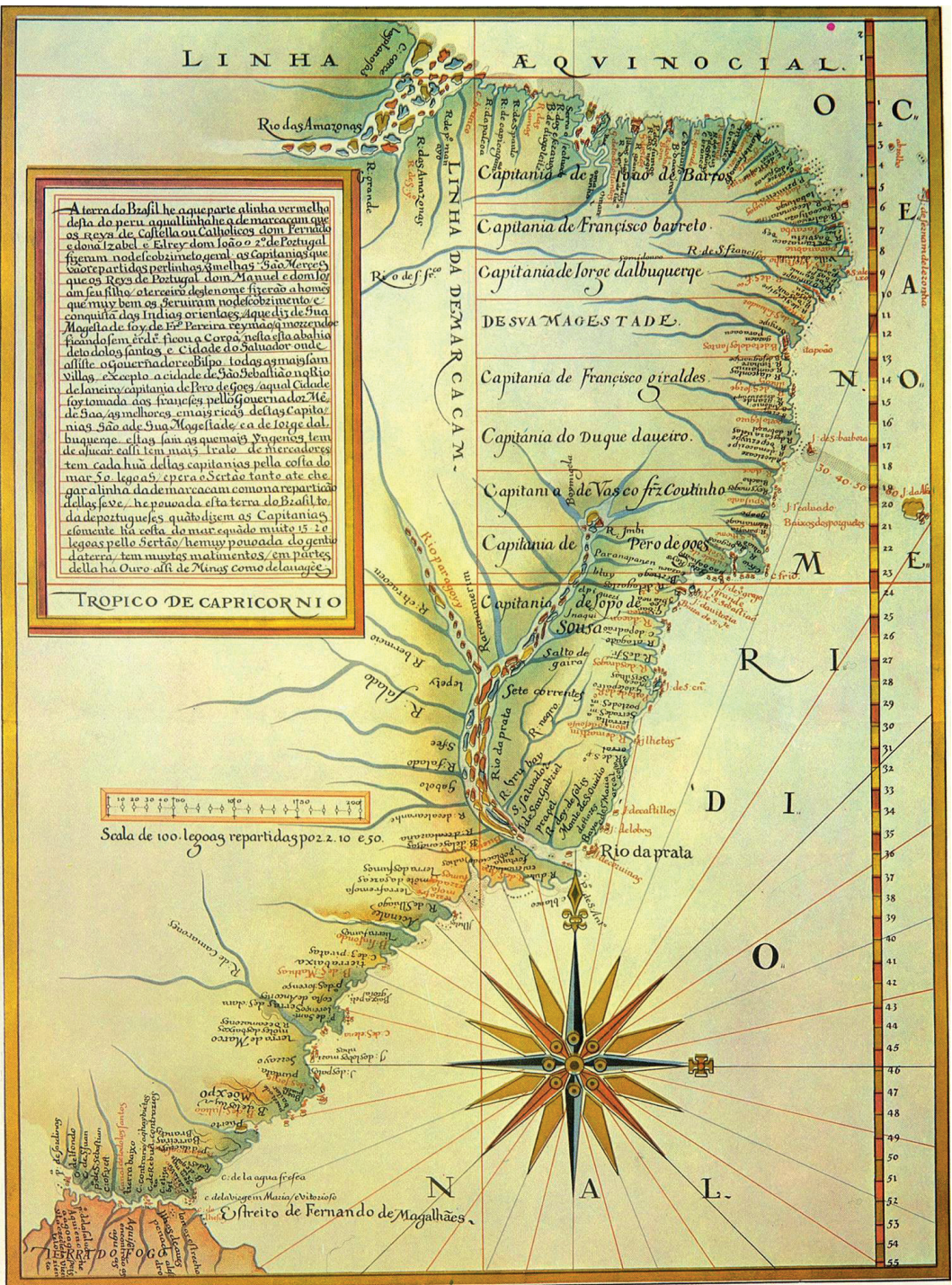

Fonte: <https://commons. wikimedia.org/wiki/File:Capitanias.jpg?uselang=pt-br> 
No final do século XVIII e início do XIX, ocorreu a primeira onda de movimentos de independência. Ela buscou a formação de confederações republicanas. O projeto não obteve sucesso, dando origem à fragmentação do território sob a colonização hispânica, especialmente quando comparado com a unidade do Império do Brasil.

A delimitação e demarcação dos estados recém-formados era a principal fonte de conflitos internacionais no século XIX. Após os processos de independência, as questões territoriais e as disputas fronteiriças foram essenciais na construção de identidades nacionais distintas para cada Estado. Ao mesmo tempo, houve uma mobilização dos centros políticos de cada Estado para territorializarse as terras ainda não incorporadas sob domínio estatal, no que é conhecido como a Conquista do Deserto (na Argentina), como "Chilenização" (no Chile, obviamente), ou como o avanço da fronteira (no Brasil e em outros países).

As imagens de território não-usado, terra vazia ou espaço vazio são evocadas até hoje, com diferentes propósitos: aliviar pressões para a reforma agrária, expandir as áreas de agronegócio e mineração em larga escala, criar coesão nacional em face de alegadas ameaças externas, justificar a securitização das fronteiras representadas pejorativamente como "abertas" ou como terra de ninguém etc. Esses processos podem ser resumidos sob 0 conceito de frente (ou front, fronteira, frontier...) cunhado no século das Guerras de Independência latino-americanas, associado ao espaço vazio, ao futuro, à terra virgem e fértil dentro de um Estado territorial moderno em construção. Assim, a fronteira americana é um movimento descrito como a expansão da civilização, a conquista do desconhecido, a criação livre de espaço. Certamente, não havia espaços vazios na América do Sul, é trabalho da imaginação colonial desconsiderar os povos indígenas. Nesse sentido, as fronteiras americanas são muito diferentes das europeias Grenzen 
(fronteira, em alemão) e frontières (também fronteira, em francês), em que se está cara a cara com o inimigo em um diálogo de forças (DORFMAN, 2013).

Líderes nacionalistas e ditaduras marcaram o século XX na maior parte do subcontinente. Governos autoritários, entre outros fatos, foram justificados pela ordem mundial bipolar. Assim, em muitos países, um estatuto especial de "áreas estratégicas de segurança nacional" foi dado a zonas fronteiriças: sua administração era uma prerrogativa do governo centralizado, as eleições foram suprimidas e meios de comunicação e partidos políticos foram silenciados com base em alegações de subversão da ordem social e influências de esquerda. Na prática, durante esse período, o conceito de fronteiras ideológicas também prevaleceu, opondo o Ocidente capitalista contra o comunismo, e permitiu a repressão da população nacional e da ação de polícia dos países vizinhos através das fronteiras, quando justificado pela luta contra a insurgência e o comunismo (ASSUMPÇÃO, 2014).

Iniciativas de integração econômica estavam presentes desde o fim da II Guerra Mundial, mas tornaram-se mais relevantes após a democratização de muitos países na década de 1980. 0 Mercosul (Mercado Comum do Sul) representa uma tentativa de diminuir a influência política e econômica norte-americana - às vezes rotulada como imperialismo - sobre o continente. Esses acordos têm motivações econômicas e impactos sobre a gestão das fronteiras, materializados em estruturas fronteiriças unificadas para melhorar e facilitar trânsitos.

Hoje, conflitos ocasionais, como Malvinas-Falklands ou as expectativas chilenas e argentinas para a Antártida, estão presentes no cenário sul-americano. No entanto, o principal conflito contemporâneo na América do Sul é impulsionado pela "guerra contra as drogas". Fronteiras e limites se sobrepõem na expansão geográfica dos projetos transnacionais de mega-mineração. Zonas 
Tampão também estão presentes sob a forma de iniciativas de preservação do meio ambiente em parques naturais transfronteiriços.

\section{PROCESSOS HISTÓRICOS}

A conquista da América, a partir do final do século XV e início do XVI, é parte de um processo conhecido como Expansão Marítima Europeia, que teve entre suas principais causas a tentativa de quebrar o monopólio italiano no comércio de açúcar, metais e pedras preciosas, especiarias, entre muitas outras mercadorias orientais. Novos continentes entraram gradualmente na rota comercial, que teve seu eixo deslocado, paulatinamente, naquela época, do Mar Mediterrâneo para o Oceano Atlântico.

A expansão da fé cristã, especialmente à luz das Cruzadas e da Reconquista da Península Ibérica dos mouros, no século XV, é um dos motivos desse processo. Ele culminou com a conquista de vários territórios na costa africana e na chegada dos espanhóis, em 1492, nas Índias Ocidentais, liderados pelo navegador genovês Cristóvão Colombo. O português Pedro Álvares Cabral chegou em 1500 no atual território brasileiro. Nas décadas seguintes, os conquistadores europeus penetraram e se estabeleceram no Novo Mundo.

\section{Conquista e colonização pelos Reinos Ibéricos}

O processo de conquista e colonização das Américas pelos espanhóis e portugueses se estendeu do final do século XV ao início do XIX. O avanço da colonização ibérica no Novo Mundo ocorreu, em grande parte, à custa das populações nativas. Grupos de diferentes troncos lingüísticos e traços culturais distintos povoavam a atual América do Sul. Os espanhóis encontraram sociedades muito complexas e organizadas, ou resquícios das mesmas, como foi o caso dos Impérios Inca (a população estimada no momento 
do contato era de doze milhões de pessoas), Maia e Asteca. Os portugueses também encontraram um mosaico de grupos, que contava com cinco a dez milhões de pessoas. Em muitos casos, havia relações de dominação entre os diferentes povos e a chegada dos europeus representou uma transferência dessa dominação.

Espanhóis e portugueses estruturaram sistemas administrativos diferentes em suas colônias. Em geral, a América Hispânica foi gradualmente dividida em quatro grandes vicereinados, a saber, o Reino da Prata, o Peru, a Nova Granada e a Nova Espanha, além de algumas capitanias. Os vice-reis e capitães gerais eram subordinados ao Conselho Real e Supremo das Índias.

A Igreja Católica foi fundamental para cimentar e dar sentido a esses fragmentos. A elite colonial foi formada por administradores peninsulares e também pelos crioulos, descendentes de espanhóis nascidos na América do Sul, os quais se dedicavam à agricultura $\mathrm{e}$ ao comércio colonial, entre outras atividades. Mestiços, indígenas e escravos africanos eram a base da sociedade colonial espanhola. O trabalho indígena era responsável por grande parte da mão-deobra nas colônias espanholas.

$\mathrm{Na}$ América Portuguesa, as atividades de exploração nas primeiras décadas do século XVI eram limitadas, basicamente, à extração do pau-brasil nas regiões costeiras através do escambo com os grupos indígenas, já que os metais preciosos só foram descobertos dois séculos mais tarde.

O domínio ibérico na América do Sul foi ameaçado por expedições colonizadoras francesas e holandesas. Assim, no segundo quartel do século XVI, o empreendimento colonial português concebeu um sistema de consignação privada do território, conhecido como capitanias hereditárias (mapa 1), sistema que já havia sido aplicado pelos portugueses nas ilhas atlânticas (Açores e Madeira) no século anterior. Perante o fracasso da 
administração de quase todas as capitanias - adversidades nos transportes e atividades agrícolas, resistência da população nativa, ausência de metais preciosos, falta de recursos - um novo sistema administrativo, centralizado, foi concebido, a partir da instauração de um Governo-Geral, inicialmente localizado em Salvador, Bahia e, posteriormente, no Rio de Janeiro. Produtos primários para os mercados estrangeiros estiveram no centro do empreendimento colonial em latifúndios escravistas (plantations). O comércio de escravos foi uma das atividades mais rentáveis nesse período, conectando a Europa, a África e as Américas através do Atlântico, de acordo com Luiz Felipe de Alencastro (2000).

Após inúmeras expedições, metais preciosos foram descobertos no interior do território, incorporando outras regiões ao domínio português e à dinâmica da colonização. Assim, no século XVIII, houve um pico na mineração. Além disso, de acordo com John Manuel Monteiro (1999), os exploradores foram responsáveis pelo apresamento massivo de indígenas para trabalhar na capitania de São Vicente (atual São Paulo). É necessário destacar os frequentes episódios de resistência à exploração dos povos indígenas e africanos.

A conquista do Novo Mundo foi concomitante com a expansão do cristianismo. No coração da América do Sul estava sendo conduzido o projeto missionário da Companhia de Jesus, liderado por Inácio de Loyola. As missões catequizaram povos indígenas nas bacias do Rio Paraná, do Rio Uruguai, e do Rio Paraguai. Esses cursos de água eram a espinha dorsal do território da missão jesuíta. Hoje, eles marcam as fronteiras dos Estados. Os jesuítas também estiveram presentes no Peru e Nova Granada, e se estabeleceram no atual território do México e dos Estados Unidos. A partir de 1750, as coroas ibéricas expulsaram os jesuítas da América com alegações de não-colaboração com expedições de demarcação e desrespeito aos representantes da Coroa, em suma, de projetos de expansão territorial. 


\section{Processos de Independência e formação dos Estados}

No início do século XIX, vários estados tornaram-se independentes. Na América do Sul, o desenvolvimento interno das colônias substituiu as importações de certos produtos das metrópoles ibéricas. Além disso, tratados assinados na Europa levaram à abertura dos portos da América do Sul para os ingleses, o que se somou ao contrabando robusto. Mudanças econômicas, juntamente com lluminismo e a invasão napoleônica da Espanha, contribuíram para o processo iniciado a partir de década de 1810 na América: as guerras de independência.

O processo de independência da América espanhola foi liderado pelos crioulos e avançou através do primeiro quartel do século XIX. Outras populações, tais como os indígenas e mestiços, lutaram tanto do lado espanhol quanto do lado crioulo. Os dois vice-reinados mais antigos, Nova Espanha e Peru, foram mais conservadores e fiéis ao Império Espanhol. Isso explica, em parte, porque essas foram as últimas regiões a tornarem-se independentes. Por sua vez, 0 vice-reinado do Rio da Prata e Nova Granada, criados durante 0 século XVIII, estimularam o processo de independência.

A grosso modo, o processo de independência da América hispânica pode ser dividido em duas fases distintas: a primeira, de 1808 a 1814, durante a Guerra da Independência Espanhola; a segunda, de 1814 a 1824, iniciada pelo governo absolutista de Fernando VII.

A primeira fase compreende um período em que as Juntas Populares foram criadas em cidades da América do Sul, como as Juntas locais espanholas, que governaram seus territórios num momento em que o soberano estava na prisão durante a guerra de independência contra Napoleão. No Novo Mundo diversas áreas proclamaram a sua independência:

- Venezuela (1811) - criação da primeira República da Venezuela; 
- Paraguai (1811) - declarou-se independente;

- Províncias Unidas do Rio da Prata (atualmente Argentina, 1813) - proclamou-se independente e veio a criar as Províncias Unidas da América do Sul, através da conquista do Uruguai, Paraguai e Alto Peru;

- Chile (1810-1814) - declarou-se independente;

- Nova Granada (1811) - dividiu-se em diversos Estados: Nova Granada, Quito, e Cundinamarca.

Quando a Guerra da Independência acabou, Fernando VII enviou tropas para a América do Sul para restaurar o domínio colonial, aprisionando e exilando líderes. Somente o Paraguai e as Províncias Unidas do Rio da Prata permaneceram independentes. No entanto, o movimento de independência reiniciou rapidamente, contando com forte apoio do Reino Unido e dos Estados Unidos.

As guerras de independência começaram a partir do Sul, das províncias independentes, e duraram quase uma década. Entre os principais protagonistas esteve José de San Martin e Simon Bolivar. Despontam, como fatos marcantes: a independência do Chile em 1818; Peru em 1821; Colômbia (Nova Granada) em 1819; Venezuela em 1821; Equador em 1822, que, juntamente com 0 primeiro e o último, com o nome de Quito, formaram a República da Gran Colômbia até 1830. A liberação final do Peru e da Bolívia, em 1824, acabou definitivamente com o governo espanhol na América do Sul.

A Banda Oriental - atualmente República Oriental do Uruguai - viu inúmeras disputas envolvendo Portugal e Espanha, bem como reivindicações expansionistas da Argentina, por um lado, e do Brasil, por outro. Só em 1828, tornou-se um estado independente (mapa 2).

Nas primeiras décadas após o processo de independência, já era possível detectar traços comuns na América Hispânica: fracasso das reivindicações unitárias; prevalência de caudilhos e a manutenção das estruturas econômicas e sociais desiguais. 
Mapa 2: Estados da América do Sul em 1864

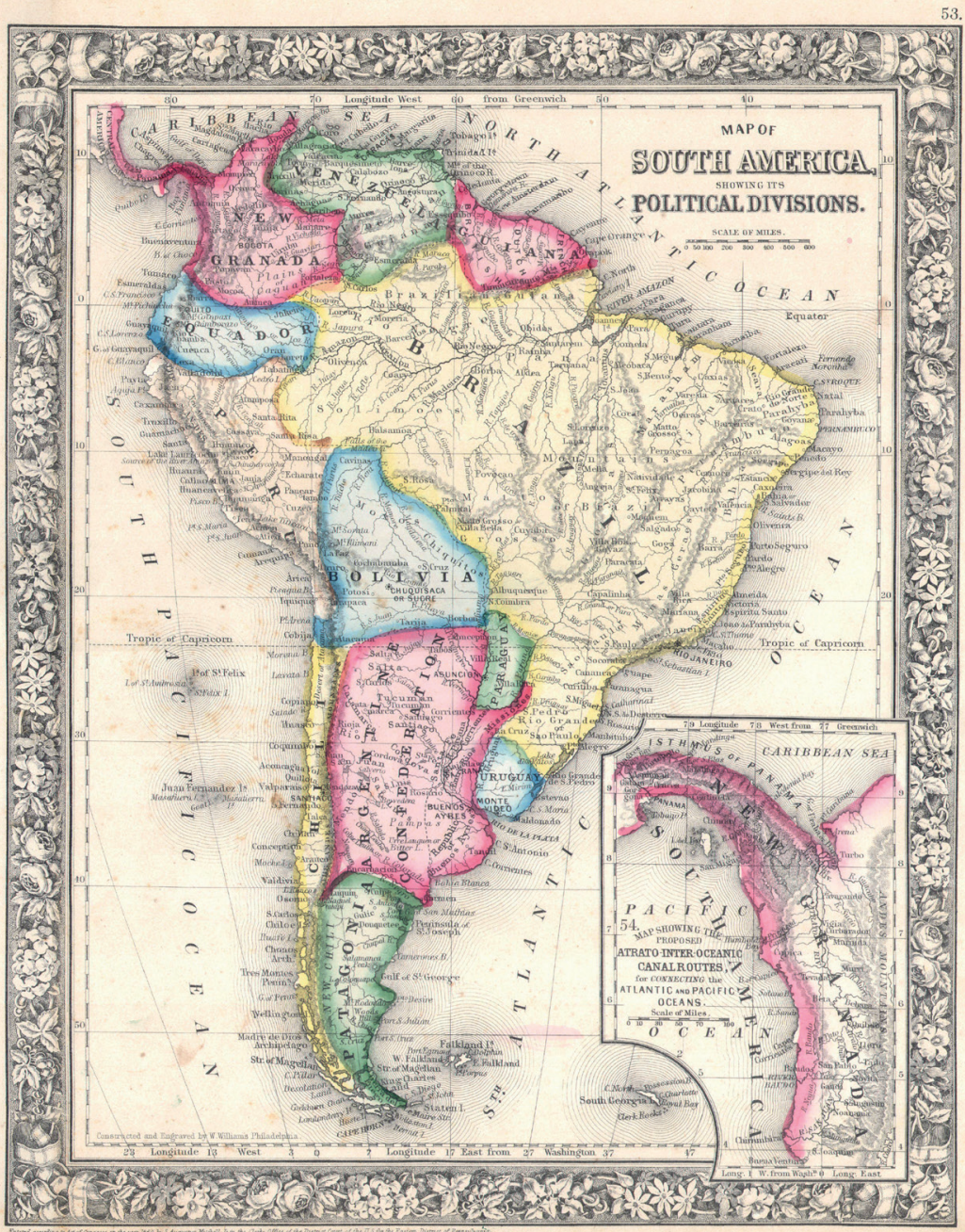

Fonte: <https://commons.wikimedia.org/wiki/File:1864_Mitchell_Map_of_South_America_-_ Geographicus_-_SouthAmerica-mitchell-1864.jpg> 
Aindependência das possessões da América do Sul de Portugal também foi influenciada pelos fatores acima destacados. O Ministro de Estado Sebastião José de Carvalho e Melo, o Marquês de Pombal, seguindo orientações Iluministas e centralizando o sistema colonial, aumentou as tarifas sobre a mineração. Os movimentos de protesto, influenciados pelos ideais da Revolução Americana e da Revolução Francesa, eclodiram pela colônia e foram reprimidos pela Coroa.

Em 1808, a corte portuguesa mudou-se para o Rio de Janeiro como resultado da invasão napoleônica na Península Ibérica. Essa situação incomum, na qual a colônia tornou-se a sede do governo geral, perturbou a relação metrópole-colônia (DIAS, 2005). Essa foi também a ocasião para a abertura dos portos brasileiros para outros países, quebrando o monopólio metropolitano. Como resultado, muitos autores tendem a considerar 1808 como 0 ano da independência do Brasil.

Os conflitos atingiram seu ápice em 1822, quando Portugal procurou restabelecer o status colonial do Brasil. Pedro I, príncipe regente e herdeiro do trono Português, decidiu permanecer no Brasil, contrariando as diretrizes metropolitanas, e o país tornou-se independente quase sem derramamento de sangue. A estrutura escravista e o Império se mantiveram, em contraste com as repúblicas abolicionistas vizinhas. O processo de independência centralizado e conservador contribuiu para a manutenção da unidade do território brasileiro.

Ao longo do século XIX, a vida política da América do Sul foi atravessada pela instabilidade política. A ideologia nacional expressou-se na literatura, na história e na geografia como forma de cimentar os grupos nos Estados recém-formado. 


\section{A CONSOLIDAÇÃO DAS FRONTEIRAS SUL-AMERICANAS}

Aindependência dos países da América do Sul não representou a cristalização de suas fronteiras. Ao longo do século XIX, uma série de conflitos armados envolvendo as novas nações ocorreu. $A$ instabilidade política começou em 1816, quando o Império do Brasil anexou a Banda Oriental (atual República Oriental do Uruguai), e só terminou em 1870, após a Guerra da Tríplice Aliança. Em paralelo, em direção ao norte da região, o movimento agora chamado Bolivarianismo militava pela unidade da América Espanhola.

\section{O expansionismo brasileiro e suas consequências}

O projeto brasileiro de controle da Bacia do Rio da Prata nas áreas agora equivalentes ao Paraguai e ao Uruguai foi evidente desde a consolidação do Império. Esse movimento, no entanto, foi sempre contido pela Argentina.

As guerras platinas foram conflitos armados decorrente desse expansionismo. Os principais conflitos foram a Guerra da Cisplatina (1825-1828), a Guerra Grande (1839-1851), a Guerra do Uruguai (1864-1865) e o último e mais profundo, a Guerra da Tríplice Aliança (1864-1870).

Apesar da imagem de relações internacionais pacíficas na América do Sul, dado o reduzido número de conflitos armados no século XX, a Guerra da Tríplice Aliança, ou Guerra do Paraguai, levou à morte mais de 350.000 pessoas e destruiu a economia $\mathrm{e}$ sociedade paraguaia.

Por um lado, esses conflitos representaram uma maior fragmentação da América espanhola, enquanto, por outro lado, também representaram o fortalecimento da unidade do Império brasileiro. 


\section{Simon Bolívar e a integração latino-americana}

Simultaneamente ao movimento expansionista do Brasil, há uma forte tendência para a união das repúblicas originadas da América Espanhola, especialmente do norte da América do Sul para o México (que na época ainda tinha os territórios agora conhecidos como Texas, EUA). Este movimento foi em grande parte centrado na figura de Simón Bolivar, presidente da Gran Colombia nos anos 20 do século XIX.

Reagindo à influência da Espanha e dos Estados Unidos sobre as novas repúblicas, o projeto da unidade territorial latinoamericana atingiu o seu pico em 1826, por ocasião do Congresso do Panamá. Mas as elites crioulas e os caudilhos regionais, que controlavam as divisões políticas menores, buscaram garantir seu poder administrativo e econômico e trabalharam para a fragmentação dos estados. Em 1865, as iniciativas bolivarianas foram interrompidas.

\section{FRONTEIRAS E CONFLITOS CONTEMPORÂNEOS}

Fronteiras não são definitivas, mas pouco mudou no desenho dos limites da América do Sul desde o início do século XX. O Quadro 1 mostra os países do continente e a extensão das suas fronteiras em 2015.

Na América do Sul, os recursos naturais são uma questão importante que, nas zonas fronteiriças, se traduzem frequentemente em parques fronteiriços. De acordo com Rebeca Steiman (2015), a maioria dos parques de conservação em países amazônicos são colocados na fronteira: a Bolívia tem mais da metade de seus parques nacionais na zona de fronteira; Peru e Brasil têm um quarto de suas unidades de proteção nos limites; Colômbia e Venezuela também têm muitas das suas reservas em regiões fronteiriças; Guiana, Suriname e Guiana Francesa têm apenas um parque natural cada - mas todos são na fronteira. 
Ainda de acordo com a mesma autora, o afastamento foi uma das principais razões para a conservação desses ecossistemas, permitindo também baixos custos de expropriação de terras. Ela aponta, finalmente, que as políticas de conservação prevaleceram sobre a fortificação, apesar do raciocínio geopolítico, uma vez que estas áreas combinam fatores como "a) a presença de recursos naturais perto da fronteira, explorados ou não; b) a existência de tensões militares; c) o reconhecimento da ocupação da terra pelos povos indígenas, cuja mobilidade transfronteiriça é intensa e de longa data" (STEIMAN, 2015, 3).

Quadro 1: Extensão dos limites e das díades dos países sul-americamos

\begin{tabular}{|c|c|c|}
\hline País & $\begin{array}{l}\text { Extensão dos } \\
\text { limites }\end{array}$ & Países Vizinhos \\
\hline Argentina & $11.968 \mathrm{~km}$ & $\begin{array}{l}\text { Bolívia } 942 \mathrm{~km} \\
\text { Brasil } 1.263 \mathrm{~km} \\
\text { Chile } 6.691 \mathrm{~km} \\
\text { Paraguai } 2.531 \mathrm{~km} \\
\text { Uruguai } 541 \mathrm{~km}\end{array}$ \\
\hline Bolívia & $7.252 \mathrm{~km}$ & $\begin{array}{l}\text { Argentina } 942 \text { km } \\
\text { Brasil } 3.403 \text { km } \\
\text { Chile } 942 \text { km } \\
\text { Paraguai } 753 \text { km } \\
\text { Peru } 1.212 \text { km }\end{array}$ \\
\hline Brasil & $16.145 \mathrm{~km}$ & $\begin{array}{l}\text { Argentina } 1.263 \mathrm{~km} \\
\text { Bolívia } 3.403 \mathrm{~km} \\
\text { Colômbia } 1.790 \mathrm{~km} \\
\text { Guiana Francesa } 649 \text { km } \\
\text { Guiana } 1.308 \mathrm{~km} \\
\text { Paraguai } 1.371 \mathrm{~km} \\
\text { Peru } 2.659 \mathrm{~km} \\
\text { Suriname } 515 \mathrm{~km} \\
\text { Uruguai } 1.050 \mathrm{~km} \\
\text { Venezuela } 2.137 \mathrm{~km}\end{array}$ \\
\hline Chile & 7.801 km & $\begin{array}{l}\text { Argentina } 6.691 \text { km } \\
\text { Bolívia } 942 \text { km } \\
\text { Peru } 168 \text { km }\end{array}$ \\
\hline
\end{tabular}


Quadro 1: Extensão dos limites e das díades dos países sul-americamos

\begin{tabular}{|c|c|c|}
\hline País & $\begin{array}{l}\text { Extensão dos } \\
\text { limites }\end{array}$ & Países Vizinhos \\
\hline Colômbia & 6.672 km & $\begin{array}{l}\text { Brasil } 1.790 \mathrm{~km} \\
\text { Equador } 708 \mathrm{~km} \\
\text { Panamá } 339 \mathrm{~km} \\
\text { Peru } 1.494 \mathrm{~km} \\
\text { Venezuela } 2.341 \mathrm{~km}\end{array}$ \\
\hline Equador & $2.237 \mathrm{~km}$ & $\begin{array}{l}\text { Colômbia } 708 \text { km } \\
\text { Peru } 1.529 \text { km }\end{array}$ \\
\hline $\begin{array}{l}\text { Guiana Francesa } \\
\text { (departamento francês) }\end{array}$ & $1.205 \mathrm{~km}$ & $\begin{array}{l}\text { Brasil } 649 \mathrm{~km} \\
\text { Suriname } 556 \mathrm{~km}\end{array}$ \\
\hline Guiana & $2.933 \mathrm{~km}$ & $\begin{array}{l}\text { Brasil } 1.308 \mathrm{~km} \\
\text { Suriname } 836 \mathrm{~km} \\
\text { Venezuela } 789 \mathrm{~km}\end{array}$ \\
\hline Paraguai & $4.655 \mathrm{~km}$ & $\begin{array}{l}\text { Argentina } 2.531 \mathrm{~km} \\
\text { Bolivia } 753 \mathrm{~km} \\
\text { Brasil } 1.371 \mathrm{~km}\end{array}$ \\
\hline Peru & $7.062 \mathrm{~km}$ & $\begin{array}{l}\text { Bolívia } 1.212 \mathrm{~km} \\
\text { Brasil } 2.659 \mathrm{~km} \\
\text { Chile } 168 \mathrm{~km} \\
\text { Colômbia } 1.494 \mathrm{~km} \\
\text { Equador } 1.529 \mathrm{~km}\end{array}$ \\
\hline Suriname & $1.907 \mathrm{~km}$ & $\begin{array}{l}\text { Brasil } 515 \mathrm{~km} \\
\text { Guiana Francesa } 556 \mathrm{~km} \\
\text { Guiana } 836 \mathrm{~km}\end{array}$ \\
\hline Uruguai & $1.591 \mathrm{~km}$ & $\begin{array}{l}\text { Argentina } 541 \text { km } \\
\text { Brasil } 1.050 \text { km }\end{array}$ \\
\hline Venezuela & $5.267 \mathrm{~km}$ & $\begin{array}{l}\text { Brasil } 2.137 \mathrm{~km} \\
\text { Colômbia } 2.341 \mathrm{~km} \\
\text { Guiana } 789 \mathrm{~km}\end{array}$ \\
\hline Total & 38.348 km & \\
\hline
\end{tabular}

Fonte: The CIA Factbook. Disponível em <https://www.cia.gov/library/publications/theworld-factbook/wfbExt/region_soa.html> 


\section{CONFLITOS FRONTEIRIÇOS}

De acordo com a Global Encyclopedia of Border Disputes, há nove disputas fronteiriças contemporâneas na América do Sul: Bolívia-Chile-Peru discutem sobre o acesso ao Oceano Pacífico; Colômbia e Venezuela têm reivindicações sobre Coquivacoa; áreas gélidas são exigidas por Argentina e Chile; as Ilhas Suarez estão em discussão entre a Bolívia e o Brasil; trechos da fronteira são reivindicados pelo Uruguai ao Brasil; o limite entre o Peru e 0 Equador ainda tem indefinições; o mesmo vale para a região de Pando entre Bolívia e Brasil; há disputas pelo uso da terra e da água entre Brasil e Paraguai e pelas as Malvinas/Falklands entre a Argentina e o Reino Unido (BRUNET-JAILLY, 2015). Vamos explorar apenas quatro deles e fazer algumas observações sobre a semelhança entre esses processos e os outros cinco casos.

\section{Disputas fronteiriças entre Brasil e Uruguai}

A fronteira entre Brasil e Uruguai foi definida em 1851, demarcada entre 1852 e 1862 e caracterizada de 1920 em diante. Hoje, dois trechos dessas linhas estão em disputa no Tribunal Internacional: a Ilha Brasileira ou Isla Brasilera e a área de Masoller ou Contestado. O uso de recursos na Lagoa Mirim está sendo negociado. A contestação é encabeçada pelo Uruguai, que argumenta a necessidade de esclarecer imprecisões na demarcação, envolvendo interpretações de toponímia e hidrografia. Os uruguaios solicitam a revisão do Tratado de Limites de 1851 (conhecido no Uruguai como o Tratado Lamas), que é percebido como favorável ao Brasil (DORFMAN E ASSUMPÇÃO, 2015).

A demarcação territorial dos novos Estados independentes na segunda metade do século XIX recorreu ao assentamento urbano. Muitas cidades foram construídas ao longo de ambos os lados da linha. Nas faixas de fronteira, a terra foi concedida a militares veteranos que poderiam cultivar em suas propriedades e, ao mesmo 
tempo, defender os territórios. A região de fronteira foi povoada e seus centros urbanos tornaram-se uma característica distinta na área e um exemplo clássico de cidades-gêmeas.

Três pontos permanecem em discussão no presente. A primeira questão é a Ilha Brasileira na tríplice fronteira entre Brasil, Argentina e Uruguai. Critérios diferentes são usados para desenhar os limites do rio entre cada uma das díades, e entram em conflito neste ponto. A ilhota de dois quilômetros de comprimento e 0,5 quilômetro de largura é atualmente brasileira, mas é reivindicada pelo Uruguai. A diplomacia brasileira rejeita essa disputa, afirmando que este limite tem bases históricas consolidadas.

A segunda contestação fronteiriça é de $220 \mathrm{~km}^{2}$, a área em forma de triângulo conhecida como Masoller ou Rincón de Artigas, no Uruguai, e como Contestado ou Vila Thomaz Albornoz no Brasil. Diferentes rios podem ser identificados como o Arroio Invernada, mencionado no Tratado de Limites de 1851. A reivindicação uruguaia data de 1934 e, desde 1974, mapas oficiais uruguaios representam a área como em disputa. Em 1985, a Vila Tomás Albornoz foi fundada com o apoio do Exército Brasileiro. Este movimento foi interpretado pelos uruguaios como uti possidetis (termo latim para "aquele que usa, possui", em outras palavras: a soberania é sustentada pela ocupação de fato).

O terceiro ponto de disputa é a Lagoa Mirim. Sua história pode ser traçada até o último quartel do século XVIII. Neste período, as coroas ibéricas estabeleceram os Campos Neutrais: devido à falta de meios técnicos, recursos humanos, ou domínio político para desenhar a fronteira como uma linha, Espanha e Portugal estabeleceram uma zona tampão triangular (GOLIN, 2015). Muitos tratados que lidam com o desenho da linha e da partilha de água natural, pesca e recursos de navegação foram feitos, alguns deles muito favoráveis ao Brasil.

Hoje, a lagoa é um laboratório para a conservação ambiental transnacional, uma vez que mantém o Projeto Piloto de Gestão 
Integrada e Sustentável da Água e Meio Ambiente na Bacia Transfronteiriça da Lagoa Mirim e do rio Quaraí, mais um exemplo de soluções de conservação em áreas de fronteira da América do Sul.

\section{Recursos hidroelétricos e o uso da terra entre Brasil e Paraguai}

Desde meados do século $X X$, agricultores brasileiros se moveram para o oeste e para o outro lado da fronteira, em território paraguaio. Hoje, algumas estimativas calculam o número de brasiguaios - ou a população descendente de brasileiros no Paraguai - como sendo cerca de 500.000 pessoas em uma população de menos de sete milhões, e de até $60 \%$ dos habitantes dos departamentos fronteiriços.

O impacto dessa migração é sentido principalmente na agricultura, uma vez que os migrantes que deixaram o Brasil compraram terras e introduziram o cultivo da soja para exportação. A partir disso, dois traços claros surgiram: a terra tornou-se muito concentrada, expulsando as populações tradicionais que não puderam se adaptar às novas estratégias comerciais e o Paraguai ascendeu como um dos principais exportadores de soja, servindose dos portos marítimos no Brasil.

Hoje, o Paraguai ocupa o sexto lugar na produção de soja e é o quarto exportador mundial. De acordo com o Departamento de Estatística, Pesquisas e Censos desse país (DGEEC), a extrema pobreza no campo foi de 24,4\% em 2007 (RED, 2014, 3). Esta configuração social traz muita tensão para a política local, que frequentemente se dissocia da análise econômica e abraça argumentações xenófobas.

Em 2014, Fernando Lugo, o então presidente do Paraguai, foi derrubado em uma crise relacionada com suas tentativas de controlar a posse da terra por estrangeiros (especialmente brasileiros e argentinos). Depois de um confronto entre a polícia 
e manifestantes sem-terra, ele foi forçado a deixar a presidência, reencenando episódios autoritários que se acreditava serem passado na América do Sul.

A integração entre o Brasil e o Paraguai também está presente na exploração conjunta dos recursos hidrelétricos do Rio Paraná, na Itaipu Binacional, construída no final de 1970. Este projeto envolveu milhares de trabalhadores, que vieram de diferentes partes do continente e permaneceram na região quando a construção foi finalizada. Isso levou a um crescimento populacional de 10 vezes (em 40 anos) nas cidades de Foz do Iguaçu (BR) e suas vizinhas Ciudad del Este (PY, anteriormente intitulada Puerto Stroessner, em referência ao ditador paraguaio) e Puerto Iguazu (AR) (PEREIRA FILHO, 2015).

A tríplice fronteira é um centro muito cosmopolita de comércio global na região. Embora a imprensa sensacionalista e a inteligência norte-americana retratem a tríplice fronteira entre Brasil, Paraguai e Argentina como um "porto seguro" para o terrorismo internacional, não há evidência de tais conexões.

\section{Ilhas Malvinas ou Falkland Islands: disputas entre}

\section{Argentina e Reino Unido}

Ilhas Falkland, ou Ilhas Malvinas, são um arquipélago localizado a 460 quilômetros da costa da Argentina, no Atlântico Sul. A soberania sobre estas ilhas rochosas foi contestada diretamente em 1833, quando a Grã-Bretanha restabeleceu seu controle. Em 1982, Argentina e Grã-Bretanha entraram em guerra pelo domínio do arquipélago. Embora derrotada, a Argentina mantém a contestação da soberania britânica sobre esse território. As ilhas são estratégicas devido à sua posição sobre as principais rotas de navegação em todo Atlântico Sul e também devido ao petróleo e recursos minerais.

Historicamente, os marinheiros britânicos tomaram posse da West Falkland Island e estabeleceram o Port Egmont em 1765. Em 
1770, devido à guerra entre a Grã-Bretanha e a Espanha, vários navios foram enviados para Buenos Aires e para o Atlântico Sul, causando a rendição da Grã-Bretanha. A Grã-Bretanha continuou, no entanto, a reivindicar as ilhas ao longo dos anos. Em 1816, a Argentina tornou-se independente e, em 1820, começou a reivindicar a soberania das ilhas, estabelecendo missões no arquipélago. Nos fins de 1832, Londres e Buenos Aires enviaram navios de guerra para as Malvinas, e a Grã-Bretanha retomou o controle sobre as ilhas no ano seguinte.

Desde então, as tensões entre Argentina e Grã-Bretanha não desapareceram. Em 1982, a Argentina invadiu as ilhas e, por dois meses, a "Guerra das Malvinas" ocorreu. Frequentemente, esse movimento da Argentina é visto mais como internamente motivado, como uma forma de unir a opinião pública a favor da Junta (a ditadura militar, na época governada por Galtieri). A guerra não só criaria um inimigo e um objetivo, mas também criaria uma cortina de fumaça que esconderia os sérios problemas sociais e econômicos internos.

A invasão começou em 3 de abril de 1982 e a Argentina se rendeu em 14 de junho do mesmo ano. Mais de 900 soldados foram mortos, e mais de 2.500 ficaram feridos. Em 15 de junho, um dia após a rendição, Galtieri anunciou sua renúncia e a ditadura chegou ao fim; Thatcher foi reeleita em 1983, aproveitando a onda nacionalista do pós-guerra.

O conflito representou uma divisão Norte-Sul do mundo, o eixo que gradualmente substituiu o Leste-Oeste. Os EUA apoiaram a Grã-Bretanha, que também contou com a ajuda de toda a Europa, especialmente da França e da Noruega; a Argentina, por outro lado, foi apoiada pelos seus parceiros latino-americanos e membros do Movimento dos Não-Aliados. O Chile, como uma exceção, ficou do lado britânico, especialmente devido ao seu interesse na Patagônia. AArgentina ainda afirma que as Malvinas são parte de seu território (WISE, 2015). 
Questões semelhantes podem ser encontrados no caso das Ilhas Sandwich do Sul e Ilhas Geórgia do Sul, que envolvem os mesmos contendores, mas sem confronto real.

\section{Disputas entre Bolivia, Chile e Peru pelo acesso ao Oceano Pacífico}

Após a Guerra do Pacífico (1879-1883), o Chile ganhou os territórios de Antofagasta e Tarapacá da Bolívia e do Peru, respectivamente. Essas terras ficavam entre a crista da Cordilheira dos Andes e o Oceano Pacífico. As reivindicações são mais importantes para a Bolívia, porque as perdas tiraram sua única saída para o mar. Desde então e até hoje, tensões e distensões se seguiram, mas as relações não foram pacificadas entre 0 Chile e os seus dois vizinhos e o caso foi repetidamente evocado para criar um consenso nacional. Em 2013, a Bolívia reapresentou a demanda ao Tribunal Internacional de Justiça pedindo a negociação sobre a sua saída para o Oceano Pacífico. Em 2015, o Tribunal aceitou essa demanda.

A Guerra do Pacífico não foi um episódio colonial, e sim entre países independentes da América do Sul. Isto significa que não foi travada para estabelecer fronteiras coloniais incertas, mas para definir os direitos de exploração e os meios de exportação de salitre. Esta guerra começou com a Bolívia e o Peru taxando as exportações de empresas chilenas. O combate entre Chile e Peru levou ao avanço das tropas chilenas e à ocupação de Lima (capital do Peru) entre os anos de 1881 e 1883. O Tratado de Amizade de 1904 definiu o território como chileno, e estabeleceu uma compensação para a Bolívia na forma da construção e concessão de uma ferrovia de 440 quilômetros ligando a capital boliviana de La Paz ao porto chileno de Arica, no antigo território peruano (ROUVIÈRE E PERRIER-BRUSLE, 2015). O mesmo se aplica à cidade peruana de Tacna, ligada a Arica por uma estrada de ferro 
de $62 \mathrm{~km}$. A primeira ferrovia foi substituída por uma rodovia e a segunda é agora uma atração turística.

Além do conteúdo nacionalista dessas disputas, a presença de atores não-estatais deve ser observada. Esses limites podem ser descritos como permeáveis aos movimentos dos indígenas Aimarás. Visto pelo Chile como uma fronteira natural, este é na verdade o território desse grupo, de mais de dois milhões de pessoas, a maioria residindo no Estado Plurinacional da Bolívia, mas também na República do Chile, República do Peru e República Argentina (HINOJOSA, 2000). Muitos problemas surgiram na última década em Tarapacá, Andes, devido aos projetos de mega-mineração e o uso excludente e predatório dos recursos. Diante do controle de fronteiras no âmbito do Plano Frontera Norte chileno, que visa reprimir o contrabando e tráfico de drogas, os trabalhadores agora enfrentam dificuldades para atravessar a fronteira.

Os principais beneficiários da exploração dos recursos naturais são as corporações transnacionais. Para estes atores, a localização periférica dos recursos não representa problemas maiores do que os relativos à passagem de mercadorias pela fronteira. Projetos de mega-mineração influenciaram positivamente 0 processo de integração regional na década de 1990 e a aceleração contemporânea da exploração e exportação no quadro da Iniciativa para a Integração da Infra-estrutura Regional da América do Sul, também conhecida como IIRSA (SCHWEITZER, 2011).

\section{ESFORÇOS DE INTEGRAÇÃO CONTEMPORÂNEOS}

A partir de um equilíbrio entre tentativas históricas para construir uma confederação no século XIX, o expansionismo brasileiro e argentino e a liberalização do comércio global contemporâneo, dois grandes blocos nasceram na região, o Mercosul (Mercado Comum do Sul) e a Comunidad Andina (Comunidade Andina das Nações).

Coincidindo com a abertura política de muitos países da 
América do Sul depois de regimes militares de décadas, essas iniciativas podem ser vistas como receptivas à situação mundial descentralização, regionalização, liberalização e a emergência de novos atores internacionais - e como a retomada dos antigos projetos de integração do século XIX. O Mercosul e a Comunidade Andina representam a formação de novas redes e são a reconstrução de antigos projetos de integração territorial.

O Mercado Comum do Sul (MERCOSUL) foi criado em 1991 e é composto por Argentina, Bolívia, Brasil, Paraguai, Uruguai e Venezuela, e os estados associados do Chile e do Peru (desde 2003), Equador e Colômbia (desde 2004), Guiana e Suriname (desde 2013). Seus objetivos são: 1) A livre circulação de bens, serviços e fatores de produção; 2) Eliminação de impostos aduaneiros e outras restrições entre os membros; 3) Estabelecimento de tarifas externas comuns e políticas para os países terceiros e a coordenação das posições dos membros em fóruns econômicos internacionais; 4) A coordenação das políticas macroeconômicas e setoriais em áreas como o comércio externo, a agricultura, a indústria, as tarifas, economia, serviços, transporte, comunicação, etc., a fim de assegurar condições adequadas de concorrência entre as partes; e, finalmente, 5) O compromisso de trabalhar para adequar a legislação para fortalecer o processo de integração (MERCOSUL, 2015).

Da mesma forma que estes projetos podem ser vistos como retomada, os seus motivos também podem ser vistos como recorrentes, uma vez que grande parte do Mercosul e da Comunidade Andina é uma resposta ao expansionismo norteamericano, especialmente em iniciativas como a Área de Livre Comércio das Américas -ALCA. A resistência à ALCA, especialmente no lado brasileiro, também representou a resistência às negociações assimétricas.

Aos poucos, há uma convergência entre a Comunidade Andina e o Mercosul, junto com o desejo de expandir mercados e economias 
de escala. Assim, as negociações para um espaço econômico sulamericano começaram, inicialmente, manifestado nas intenções de criação da Área de Livre Comércio Sul-americana - ALCSA em 1993. Na prática, porém, é em 2000 com a IIRSA que estas negociações alcançam certas regiões.

A IIRSA se foca em transportes, energia e redes de telecomunicações, além de redes econômicas e reformas tarifárias. Estruturada em eixos, a IIRSA pretende ligar os centros de produção aos mercados dentro e fora do continente. Isto é feito através da construção de infraestrutura que liga as costas do Atlântico e do Pacífico da América do Sul, respondendo às deficiências históricas nas terras interiores. Vários projetos da IIRSA já estão em andamento ou concluídos, incluindo gasodutos, ferrovias, hidrovias e estruturas de condução de eletricidade, mais recentemente sob a bandeira do Conselho Sul-Americano de Infraestrutura e Planejamento (COSIPLAN).

Em 2004, a convergência entre Mercosul-CAN move-se mais à frente e a CASA (Comunidade Sul-Americana de Nações) é formada, mais tarde renomeada de União das Nações Sul-Americanas (UNASUL ou UNASUR). A UNASUL não só abrange todas as nações da região, mas difere-se essencialmente pela sua natureza política, não econômica. Visto como o espaço do exercício do poder brasileiro, a UNASUL, na verdade, representa a regionalização que procura coordenar as questões securitárias do subcontinente dentro do subcontinente, bem como alavancar projetos como a construção de uma cidadania comum e 0 aprofundamento da integração infraestrutural.

A UNASUL também atua na tentativa de reverter a guerra contra as drogas travadas pelos EUA na Colômbia, na Venezuela e em outros países da região, que implica em enormes perdas humanas e erosão institucional. Uma nova visão sobre o problema das drogas foi recentemente proposta, deixando de lado a mera punição e centrando esforços nos seres humanos e em sua saúde (UNASUR, 2015). 


\section{REFERÊNCIAS}

ALENCASTRO, Luiz Felipe de. O Trato dos Viventes: A Formação do Brasil no Atlântico Sul. São Paulo: Companhia das Letras, 2000.

ASSUMPÇÃO, Marla Barbosa. A Fronteira Germinada de Santana do Livramento-Rivera como Marco das Conexões Políticas Regionais e Internacionais: repressão e resistência em Áreas de Interesse da Segurança Nacional (1964-1973). Dissertação (Mestrado em História), UFRGS, 2014.

BRUNET-JAILLY, Emmanuel (ed.). Border Disputes: A Global Encyclopedia, Santa Barbara: ABC-CLIO

DIAS, Maria Odila Leite da Silva. A Interiorização da Metrópole e outros estudos. São Paulo: Alameda Casa Editorial, 2005.

DORFMAN, Adriana. A condição fronteiriça diante da securitização das fronteiras do Brasil. In: NASCIMENTO, Durbens; PORTO, Jadson Luis Rebelo (orgs.) Fronteiras em perspectiva comparada e temas de defesa da Amazônia. Belém: EDUFPA, 2013, v. 1, p. 96-124.

DORFMAN, Adriana; ASSUMPÇÃO, Marla. Uruguay-Brazil: Brazilian Island. In: Brunet-Jailly, Emmanuel (ed.). Border Disputes: A Global Encyclopedia, Santa Barbara: ABC-CLIO, 2015.

GOLIN, Tau. As fronteiras das águas do Brasil Meridional. In Raddatz, Vera Lucia Spacil; Müller, Karla Maria (orgs.). Comunicação, cultura e fronteiras. ljuí: Ed. Unijuí, 2015.

HINOJOSA, Alfonso. Idas y venidas: Campesinos tarijeños en el norte argentino. La Paz: Fundación PIEB, 2000.

MERCOSUR. En pocas palabras. 2015. Disponível em: <http://www. mercosur. int/t_generic.jsp? contentid=3862\&site=1\&channel=secretaria>. Acesso em janeiro de 2015.

MONTEIRO, John Manuel. Negros da Terra. Índios e Bandeirantes nas origens de São Paulo. São Paulo: Companhia das Letras, 1999.

PEREIRA CARNEIRO FILHO, Camilo. Brazil-Paraguay. In: Brunet-Jailly, Emmanuel (ed.). Border Disputes: A Global Encyclopedia, Santa Barbara: ABC-CLIO, 2015

RED por una América Libre de Transgénicos, Alianza Biodiversidad. 2014. Informe de la gira de verificación sobre los impactos de la soja transgénica en Paraguay. Biodiversidad: sustento y Culturas, January 79. Disponível em: $<$ <ttps://www.grain.org/article/entries/4890>. 
ROUVIÈRE, Laetitia; PERRIER-BRUSLÉ, Laetitia. Bolivia-Chile-Peru: Sea Access. In: BRUNET-JAILLY, Emmanuel (ed.). Border Disputes: A Global Encyclopedia, Santa Barbara: ABC-CLIO, 2015.

SCHWEITZER, Alejandro. Fronteras internacionales, recursos naturales e integración regional en el Cono Sur de America del Sur. Para Onde?!. v. 5, n.2, 2011.

STEIMAN, Rebeca. Territórios da conservação: novos arranjos espaciais na zona de fronteira da Amazônia Brasileira. III Seminario Internacional de los Espacios de Frontera. 2015.

UNASUR. Consejo sobre el problema mundial de las drogas (CSPMD). 2015. Disponível em: <http://www.unasursg.org/es/node/30>. Acesso em setembro de 2015.

WISE, Nicholas. Argentina-Great Britain: Falkland Islands/Islas Malvinas. In: BRUNET-JAILLY, Emmanuel (ed.). Border Disputes: A Global Encyclopedia, Santa Barbara: ABC-CLIO, 2015.

ZUSMAN, Perla. Cap III - Repensar las fronteras. Tierras para el rey. Tres fronteras en la construcción colonial del territorio del Virreinato del Rio de la Plata (1750-1790). Tese (Doutorado em Geografia), Univ. Autónoma de Barcelona, 2000. 
